\title{
LETTERER-SIWE DISEASE
}

\author{
BY \\ A. A. MacKELVIE, F.R.C.S.Ed., and W. WALLACE PARK*, M.B. \\ From the Stirling Royal Infirmary and the Royal College of Physicians Laboratory, \\ Edinburgh
}

(RECEIVED FOR PUBLICATION JUNE 22, 1949.)

The term Letterer-Siwe disease was applied by Abt and Denenholz (1936) to a condition first described in detail by Letterer (1924) and later recognized by Siwe (1933) as a well defined clinicopathological syndrome.

Letterer-Siwe disease is an illness of infants, almost invariably fatal, and of unknown aetiology. The main clinical features are an age incidence from two months to two years; an indefinite onset with no specific symptomatology; a febrile course lasting for a few weeks or a few months to death; generalized enlargement of the lymph nodes, enlargement of the spleen, and often of the liver as well; a haemorrhagic tendency, commonly producing a purpuric or ecchymotic skin rash most marked shortly before death; hypochromic anaemia, sometimes severe; destructive lesions in bone, commonly in the skull, rarely, if ever, in the bones of the hands and feet, but often occurring elsewhere in the skeleton, e.g. in the ribs, pelvis, humerus, femur, and may be clinically silent or associated with pain and tenderness, with or without overlying soft tissue swelling; sometimes mottling of the lung fields on $x$-ray examination; less commonly, secondary bacterial infection, such as otitis media or angina of the throat, and leucocytosis; no apparent hereditary or familial incidence. The characteristic pathological feature is excessive hyperplasia of the reticulo-endothelial tissue throughout the body, particularly in the spleen, lymph nodes, and skin.

Of the nine patients with Letterer-Siwe disease whose case-reports were analysed by $\mathrm{Abt}$ and Denenholz (1936), all had splenomegaly, a petechial and ecchymotic skin eruption, a moderate continued fever, and moderate to severe secondary anaemia, and all but one showed enlargement of the lymph nodes. There were alterations in the bone marrow cytology in eight of the patients (no details given in the remaining case) mainly in the form of proliferation of large, pale, histiocytic cells. Four of the patients showed lesions in bone.

The most helpful factor in reaching a correct diagnosis would be the knowledge that such a recognized syndrome existed. Biopsy of tissue from the spleen, bone marrow, or of a lymph node has

* Working with a grant from the British Empire Cancer Campaign. been mentioned as a possible aid to diagnosis. To judge from reported cases, and certainly from the findings in our own case, the histological picture is not so specific that Letterer-Siwe disease can be diagnosed outright from biopsy. A biopsy of the three tissues could indicate reticulum cell overgrowth, and to that extent confirm a clinical diagnosis of Letterer-Siwe disease, but biopsy of a lymph node would probably always be the most useful. Much more than biopsy of the spleen or bone marrow it offers to the pathologist the chance of being able to exclude some of the other conditions which may cause generalized lymph node enlargement.

Conditions which have been mentioned as entering into the differential diagnosis include aleukaemic leukaemia, Hodgkin's disease and lymphosarcoma, generalized osteitis fibrosa, a local bone neoplasm or a metastasizing neoplasm with spread to bones, tuberculous disease of bone, myelomatosis, generalized xanthomatosis, 'von Jaksch's anaemia', and typhoid fever.

Since the article by Abt and Denenholz at least five other examples of the Letterer-Siwe disease complex have been described by Freud, Grossman, and Dragutsky (1941), Wallgren (1940) two cases, Gross and Jacox (1942), Jaffe and Lichtenstein (1944). This makes a total of 14 so far reported, but it is quite clear that many other examples were reported earlier under different names, for instance non-lipoid histiocytosis, reticulo-endotheliosis, or aleukaemic reticulosis, before their identity was realized. The name given to the disease by Oberling and Guérin (1934), 'acute reticulosis of infants,' is in many ways preferable to its present eponymous title. Letterer-Siwe disease is now considered to be only one variant of a basic granulomatoid disorder which appears on other occasions as 'infective' reticulo-endotheliosis, Hand - Schüller - Christian disease, and eosinophilic granuloma of bone. Transitional stages between these more dist nctive forms of the disorder are relatively common. Jaffe and Lichtenstein (1944), for example, considered that the case described by Hand, which led to the association of his name with those of Schüller and Christ an in the name Hand-Schüller-Christian disease, was more probably an example of LettererSiwe disease. 
Amongst the nine cases accepted by Abt and Denenholz as examples of Letterer-Siwe disease was one of a series of four (Case No. 4) described by Gittins (1933) in his study of - Anaemia and ReticuloEndotheliosis.' Apart from this we have not found any examples of Letterer-Siwe disease reported in the British literature, and our case report appears to be the first account in this country of Letterer-Siwe disease since the disease was recognized as a clinico-pathological entity.

\section{Case Report}

Baby A.W., a girl, aged 7 months, was seen on June 3 , 1947, at the Outpatient Department of Stirling Royal Infirmary. Except for a history of possible whooping cough at the age of 14 weeks, the child had had no illness until four weeks before, when a swelling appeared behind the left ear. This swelling had been incised and treated as an abscess

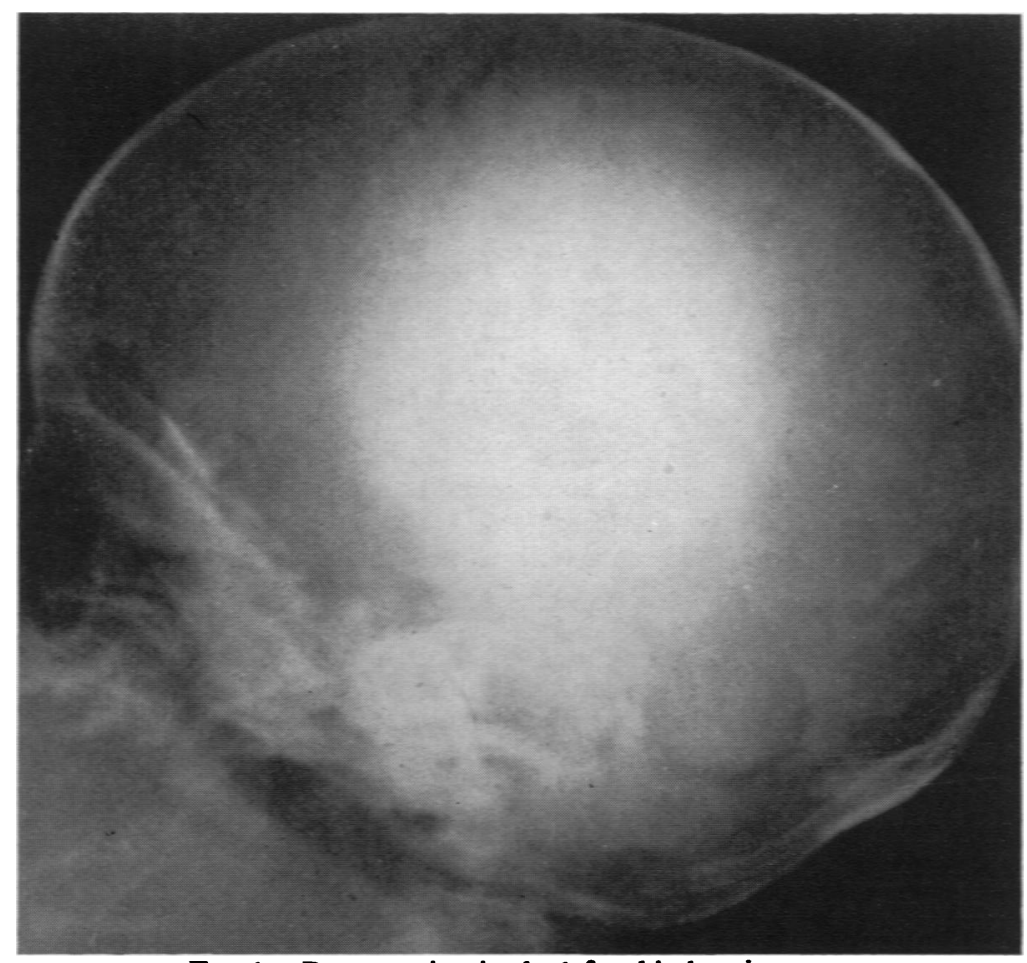

Fig. 1.-Bone erosion in the left orbital region.

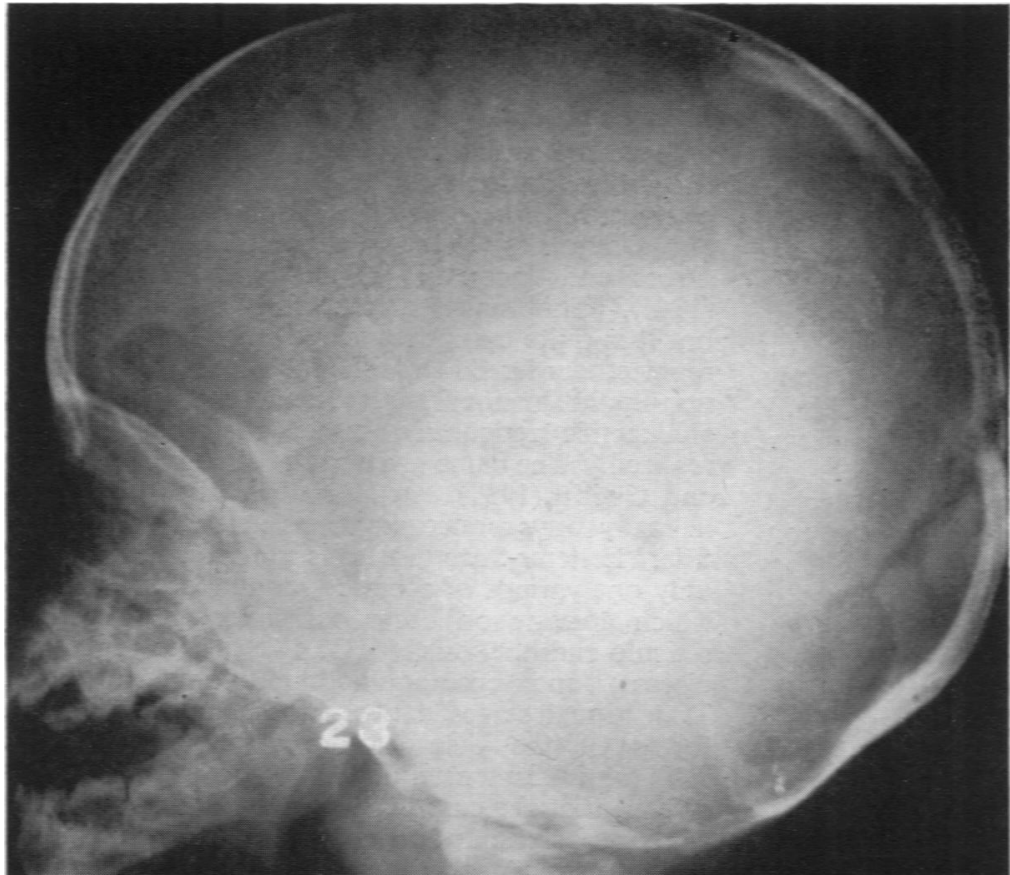

Fig. 2.- Increase in orbital bone erosion and areas of similar bone change in the occipito-parietal area. two weeks previously at another hospital where an otologist had reported that there was no middle-ear or mastoid disease. Three weeks before being seen at Stirling the child had developed a rash on the anterior thoracic and abdominal walls. She was fretful and was not gaining weight. There was no apparent pain and no history of diarrhoea.

Examination showed a pale child with a soft swelling, not red but tender, above the left mastoid area. Over the swelling was a small healed incision. The left upper cervical lymph nodes were slightly enlarged. No other lymph node enlargement was found, nor any enlargement of the liver or spleen. Over the anterior aspect of the lower thorax and upper abdomen there was a scaly, macular, petechial rash. The Wassermann reaction was negative, as was that of both parents. X-ray examination of 
the left mastoid area showed no bone abnormality, but the plates were not very satisfactory.

The child was admitted to hospital on June 7, 1947. It was then found that a small firm swelling

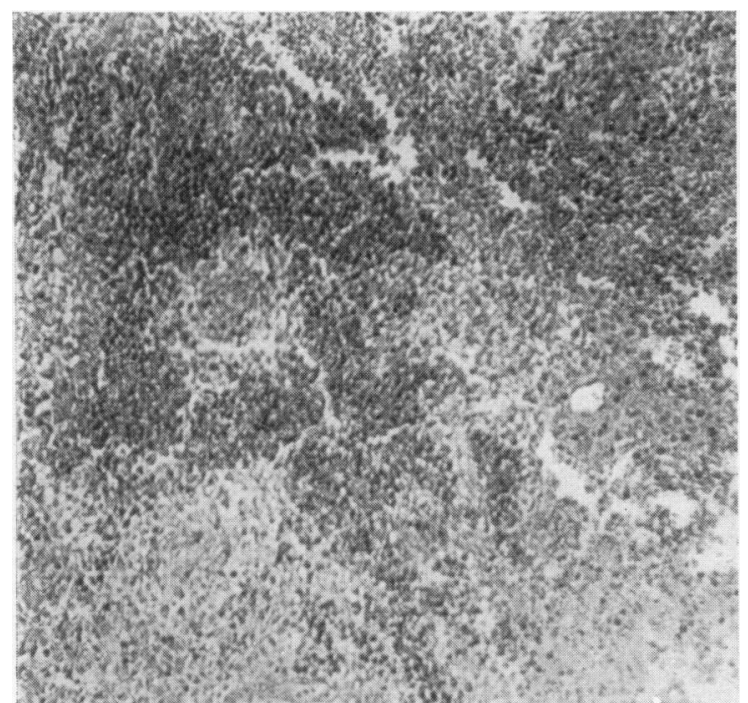

Fig. 3.-Highly cellular tissue. The dark areas are dense collections of eosinophil leucocytes. $\times 80$.

had developed in the upper outer area of the left orbit. X-ray plates showed an area of bone erosion (Fig. 1).

On June 21, 1947, the mastoid swelling was opened, and the soft, greyish tissue curetted out was sent for pathological examination.

This first biopsy specimen was received at the Royal College of Physicians Laboratory, Edinburgh, a few days later. It consisted of three small fragments of soft grey tissue. Microscopically the tissue was highly cellular and without trace of organized anatomical structure. There was a background of moderately small, uniform cells, sometimes in loose masses, sometimes forming cellular sheets, and much extravasated blood. Here and there were small, well defined blood vessels. The tissue was widely infiltrated with polymorphonuclear leucocytes of which many were eosinophils. There were also many lymphocytes, a few plasma cells, and an occasional non-specific multinucleated giant cell. The appearances were not diagnostic and indicated a subacute or chronic inflammatory process with some patchy fibroblastic activity. On this occasion no special significance was attached to the eosinophil leucocytes.

Penicillin (50,000 units three-hourly) therapy was begun on June 23 . The swelling above the left eye was larger. By July 10 the mass behind the ear was somewhat smaller, but an abscess had appeared in the neck below the ear. Penicillin $(3,900,000$ units) had been given.

On July 17 it was noted that the swelling in the left orbit had increased greatly, was fluctuant, and was causing strabismus. X-ray examination showed an increase in the area of bone erosion (Fig. 2). Two days later the orbital swelling was curetted, and a specimen of similar soft grey tissue with small yellow and red areas was again sent for examination.

This second biopsy specimen consisted of many small irregular fragments of soft tissue and, as in the first specimen, microscopic examination showed a mass of highly cellular, haemorrhagic tissue but there were three main differences: (a) The predominant cells were better preserved and slightly larger, with more cytoplasm and a more regular nuclear outline. Though still not specific the appearances were now those of proliferating reticulum cells. An occasional (reticulum) cell was in mitosis. (b) Eosinophil polymorphonuclear leucocytes were numerous and prominent, forming many large dense aggregations (Figs. 3 and 4). No cells could be distinguished with certainty as eosinophil myelocytes. (c) Multinucleated giant cells were more numerous, still without diagnostic features but not unlike osteoclasts (Fig. 5). Appearances otherwise were much the same as before: a small amount of fibroblastic proliferation, many lymphocytes, comparatively few neutrophil 'polymorphs,' and occasional plasma cells.

The disease process appeared to be of the nature of a reticulum cell or histiocytic overgrowth with accompanying inflammatory changes, predominantly as an eosinophil reaction. It brought to mind the so-called eosinophilic granuloma of bone, and this diagnosis was suggested as the most likely. There were no histological findings to suggest neuroblastoma or Wilm's tumour.

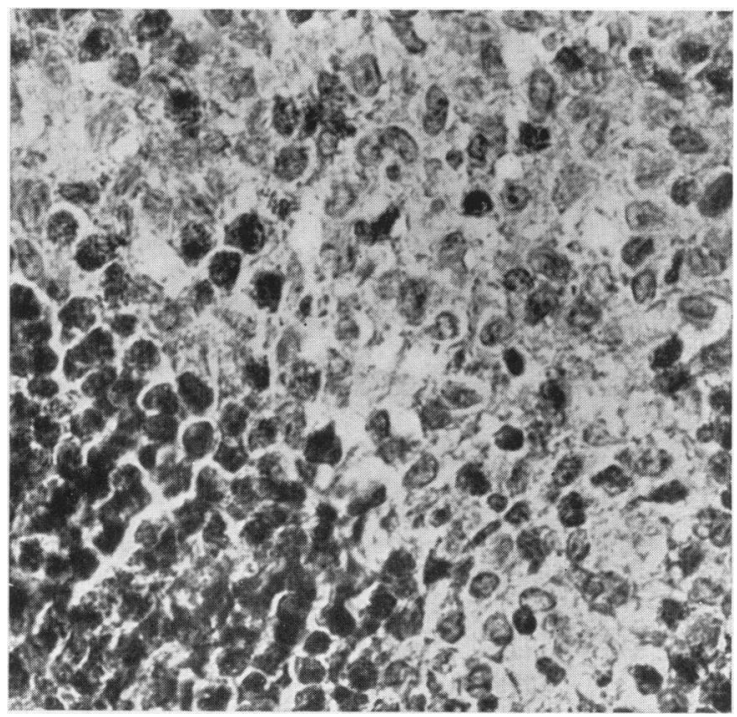

FIG. 4.-High-power view of the same area as in Fig. 3. The dark cells are intensely eosinophilic. The less hyperchromatic cells are of reticulum cell type. $\times \mathbf{3 5 0}$. 
X-ray examination on Aug. 8, 1947, showed a further area of bone erosion in the occipito-parietal region.

\section{Peripheral Blood Examination:}

Total red blood count, $4,480,000$ per c.mm.

Total white blood count, 25,800 per c.mm.

Neutrophil polymorphs $\quad 50^{\circ} \%=12,900$ per c.mm.

Eosinophil polymorphs $\quad 4^{\circ} \%=1,032$ per c.mm.

Basophil polymorphs

Large lymphocytes

Small lymphocytes

Monocytes

nil

$4^{\circ} \%=1,032$ per c.mm.

$40 \%=10,320$ per c.mm.

$2 \%=516$ per c.mm.

Individual erythrocytes and leucocytes showed no abnormalities. No primitive cells were seen. The figures indicated a general leucocytosis and a slight absolute eosinophilia.

Biopsy of Sternal Bone Marrow. The material consisted of cellular tissue with cells of the erythroid and granular series present in average normal proportion. Erythropoiesis was normoblastic and no megaloblasts were seen. Eosinophil myelocytes were a little more numerous than usual. Megakaryocytes were plentiful. There were no abnormal cells, and no indication of any leukaemic process, myeloma, or other neoplasm.

\section{BloOd Chemistry:}

Blood cholesterol, $118 \mathrm{mg}$. $\%$

Blood phosphorus, $3.5 \mathrm{mg} . \%$.

X-ray examination of all bones on Aug. 9, 1947, showed areas of irregular absorption and erosion in the left iliac bone, the left mastoid and orbital regions, and in the occipito-parietal region (Fig. 6).

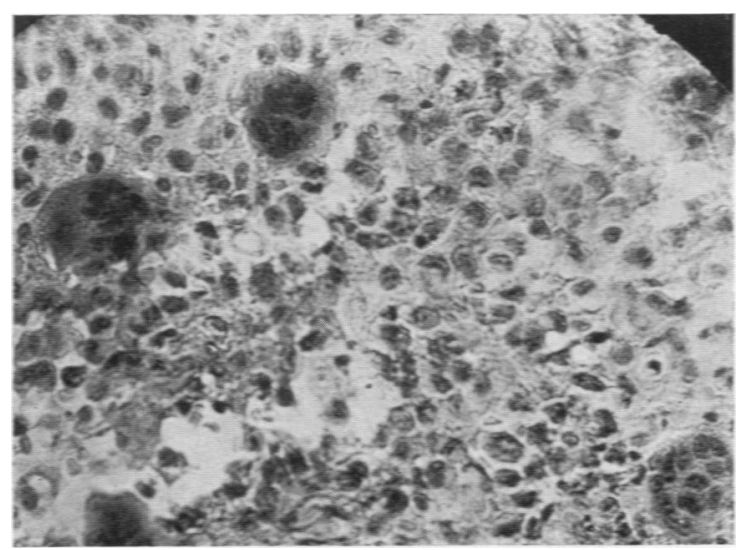

FIG. 5.-Multinucleated giant-cells. $\times 300$.

An irregular pyrexia had continued since admission to hospital, and the general condition of the patient had deteriorated steadily. The petechial rash spread up the left side of the neck and head, and there was slight enlargement of the lymph nodes of both sides of the neck. No treatment, including the full course of penicillin, had produced any improvement. The baby died on Aug. 12, 1947.

A full post-mortem examination was made by Dr. W. P. Weir of the Western Infirmary, Glasgow,

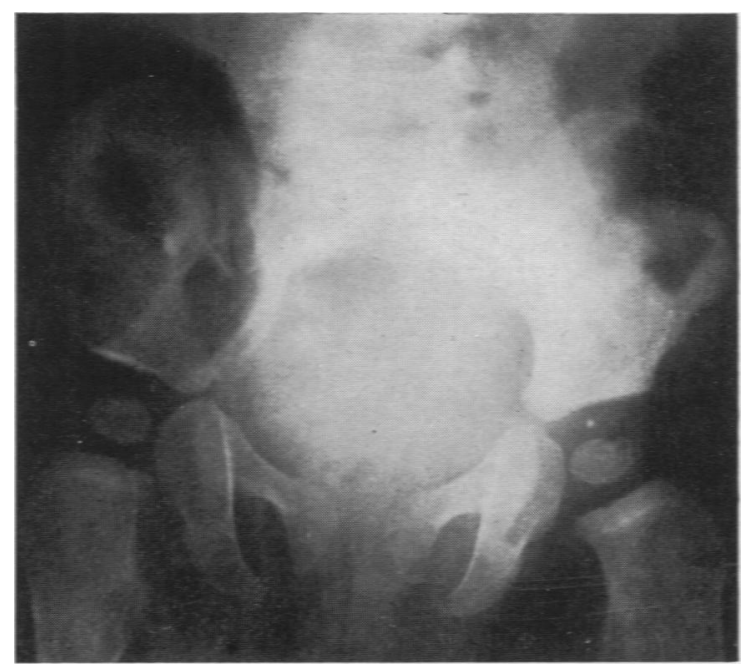

FIG. 6.-Irregular erosion and absorption in the left iliac bone.

who is reporting his findings in a separate article in preparation. He has kindly allowed us to make use of his notes.

The macroscopic findings included enlargement of the spleen, areas of tumour-like growth in the left vertex, left mastoid region, and in the wing of the left ilium, but no gross abnormality in the lungs, thymus, mediastinal, and abdominal lymph nodes.

Microscopically, abnormal reticulum cell proliferation, focal and diffuse, could be seen in the lymph nodes, lungs, skin, one of the lesions in bone, and especially in the spleen. Besides this, some areas of the lesions in bone still retained the appearances of eosinophilic granuloma. It was not until the tissues obtained at necropsy were examined microscopically, and the findings, together with the clinical data, compared with previous accounts in the literature, that Letterer-Siwe disease was diagnosed. Seen in retrospect the clinico-pathological syndrome presented by this patient was an almost typical example of the condition.

\section{Discussion}

Mallory (1942) and Jaffe and Lichtenstein (1944) have given full descriptions and discussions of Letterer-Siwe disease and its relationship to the group of reticulo-endothelioses, Schüller-Christian disease, and eosinophilic granuloma of bone, and only a short outline of current views will be given here.

Abt and Denenholz (1936) made six categories of the disorders of the reticulo-endothelial system. 
Lipoid storage diseases (Schüller-Christian, Niemann-Pick, and Gaucher diseases), certain leukaemias, neoplasms such as reticulum cell sarcoma, and Hodgkin's disease made up four of the categories. The remaining two were first, reticulo-endothelial hyperplasias where acute infection, presumably primary and causal, was present; and secondly, reticulo-endothelial hyperplasias where there was no obviously related infection. The non-infective category comprised Letterer-Siwe disease. Wallgren (1940) considered that the last two categories were in fact identical and that infection played no part in the aetiology. Further, he drew attention to the close relationship of Letterer-Siwe disease to Schüller-Christian disease and described two illustrative clinical examples. The first in his opinion was "intermediate between so-called infectious reticulo-endotheliosis and Letterer-Siwe disease,' and the second intermediate 'between the latter malady and Schüller-Christian disease.' He gave a list of 23 reported cases, each an example of infectious reticulo-endotheliosis or Letterer-Siwe disease or Schüller-Christian disease, and arranged them in order according to their duration. In this way he showed that there were many transitional types between one disease and the others, and he stated that neither Letterer-Siwe disease nor Schüller-Christian disease had any characteristic feature that could not occur in the other. The relationship between these two diseases had been noted as well by Flori and Parenti (1937) and by Glanzmann (1940). In the year after Wallgren's observations Farber (1941) also drew attention to the close relationship and made two further contributions to the pathology of the underlying disorder. First, he was unwilling to accept Schüller-Christian disease as belonging to the group of simple lipoid storage diseases; secondly, he related both Letterer-Siwe disease and SchüllerChristian disease to the so-called eosinophilic granuloma of bone, remarking that all three were conditions which 'represent variations in degree, stage of involvement, and localization of the same basic disease process.'

It would be appropriate to make a few remarks here on 'eosinophilic granuloma of bone,' an uncommon condition which has not received much publicity in Great Britain up to date, but is a condition which is important when it arises because of its simulation of a malignant tumour despite an entirely favourable prognosis.

The condition was originally described by Otani and Ehrlich (1940) and Lichtenstein and Jaffe (1940) independently. It is a circumscribed destructive lesion of bone, occurring usually in children or adolescents and sometimes in young adults, monostotic or polyostotic in distribution, and liable to affect almost any bone other than those of the hands and feet. There may or may not be localizing symptoms, expansion of the bone or fracture. Jaffe and Lichtenstein (1944) stated that there was nothing distinctive about the radiological appearances of the individual lesion, an area of rarefaction, generally oval or circular (often with a punched-out appearance when in the calvarium), starting in the interior of a bone and growing, usually rather rapidly, to involve the cortex which may become perforated. In different cases the findings may simulate osteomyelitis, primary bone neoplasm, multiple myeloma, Ewing's tumour, a metastasizing carcinoma, or Schüller-Christian disease. Histologically the lesion is characterized by sheets of proliferating histiocytic cells with which are mingled varying numbers of eosinophil leucocytes and scattered multinucleated giant cells. The prognosis with regard to healing of the individual lesion is good: "The lesions do not tend to become scarified, collagenized and lipidized, heal rapidly after simple curettage even without supplementary roentgen irradiation of the site, and may indeed heal by resolution even without any therapeutic intervention whatever' (Jaffe and Lichtenstein, 1944).

Both Wallgren's contentions, mentioned above, have been accepted by authorities on the subject. Thus Mallory (1942) has agreed that SchüllerChristian disease is not of the lipoid-storage group of diseases but a manifestation of the same granulomatous process that underlies Letterer-Siwe disease. According to Jaffe and Lichtenstein (1944) ' . . . it is not Schüller-Christian disease but only xanthoma tuberosum multiplex that constitutes the cholesterol lipid disorder analogue of Gaucher's disease and Niemann-Pick disease.' Mallory and Jaffe and Lichtenstein again agree in adding eosinophilic granuloma of bone as a further clinical expression of the same disorder, a reticulo-endothelial granulomatosis varying in distribution within the body and of uncertain aetiology.

Of the different manifestations of the disorder, Letterer-Siwe disease, with its widespread lesions and fatal course, is usually well defined; eosinophilic granuloma of bone, with its restricted skeletal localization and favourable prognosis, is also usually well defined; whereas Schüller-Christian disease is still a rather miscellaneous group. To quote yet again from the later article of Jaffe and Lichtenstein (1944), they have said '... on the one hand, in the early stages of evolution of Letterer-Siwe disease one may find destructive skeletal lesions resembling cytologically those of eosinophilic granuloma of bone, and, on the other hand, in its chronic stages Letterer-Siwe disease takes on the aspect of SchüllerChristian disease, the skeletal and even certain visceral lesions undergoing lipogranulomatous transformation.' This means that the classification on histological grounds of a given example of the disorder may be difficult, and the literature contains many accounts of illustrative transitional types (Guizetti (1931), Merritt and Paige (1933), Grady and Stewart (1934), Hertzog, Anderson, and Beebe (1940), Curtis and Cawley (1947), Weinstein, Francis, and Sprofkin (1947)). Clinically, however, there is a broad correlation of the different disease groups 
with age, and Mallory (1942) has summarized the position clearly (p. 956) as follows:

\begin{abstract}
'Strongly suggestive evidence therefore lies at hand that all these various syndromes represent a single entity-rapidly fatal in the infantile forms, which have been described as Letterer-Siwe's disease and reticulo-endotheliosis; chronic, but still of serious import because of the likelihood of cerebral and hypophyseal involvement, in early childhood (Hand-Schüller-Christian's disease); and comparatively benign in later childhood or in the adult, where the usual picture is that of eosinophilic granuloma. Proof of this identity must of course await the discovery of the etiology.'
\end{abstract}

The aetiology of Letterer-Siwe disease and of the other variants of systemic reticulo-endothelial granulomatosis is still unknown. The possibilities appear to be an endogenous metabolic disturbance, a specific infection, or varying behaviour of a neoplastic process. Van Creveld and Ter Poorten (1935) thought that infection was probably primary and causal though they did mention the possibility of its being secondary and sequential. Wallgren (1940) thought that infection played no part at all in the aetiology. Mallory and Jaffe and Lichtenstein have expressed the opinion that the condition is an inflammatory histiocytosis arising in response to some as yet unknown specific infectious agency, though attempts to isolate bacterial organisms or a virus have not succeeded so far. No attempt was made to isolate organisms or virus from our patient. All we can say is that if there was an organismal cause the organism concerned was not affected by some $4,000,000$ units of penicillin given over a period of 17 days.

\section{Summary}

An example of acute reticulosis of infants (Letterer-Siwe disease) is described.

A short summary is given of current views on the inter-relationships and probable underlying identity of this condition with 'infective' reticulo-endotheliosis, Hand-Schüller-Christian disease, and eosinophilic granuloma of bone.

\section{REFERENCES}

Abt, A. F., and Denenholz, E. J. (1936). Amer. J. Dis. Child., 51, 499.

Curtis, A. C., and Cawley, E. P. (1947). Arch. Derm. Syph., Wien, 55, 810.

Farber, S. (1941). Amer. J. Path., 17, 625.

Flori, A. G., and Parenti, G. C. (1937). Riv. clin. pediat., 35, 193. (Cited by Jaffe and Lichtenstein.)

Freud, P., Grossman, J., and Dragutsky, D. (1941). Amer. J. Dis. Child., $62,776$.

Gittins, R. (1933). Arch. Dis. Childh., 8, 367.

Glanzmann, E. (1940). Ann. paediat., Basel, 155, 1. (Cited by Jaffe and Lichtenstein.)

Grady, H. G., and Stewart, H. L. (1934). Arch. Path., 18, 699

Gross, P., and Jacox, H. W. (1942). Amer. J. med. Sci., 203, 673.

Guizetti, H-U. (1931). Virchow's Arch., 282, 194.

Hertzog, A. J., Anderson, F. G., and Beebe, G. W. (1940). Arch. Path., 29, 120.

Jaffe, H. L., and Lichtenstein, L. (1944). Arch. Path., $37,99$.

Letterer, E. (1924). Frankfurt Z. Path., 30, 377. (Cited by Abt and Denenholz.)

Lichtenstein, L., and Jaffe, H. L. (1940). Amer. J. Path., 16, 595.

Mallory, T. B. (1942). New Eng. J. Med., 227, 955.

Merritt, K. K., and Paige, B. H. (1933). Amer. J. Dis. Child., 46, 1368.

Oberling, Ch., and Guérin, M. (1934). Sang, 8, 892.

Otani, S., and Ehrlich, J. C. (1940). Amer. J. Path., 16, 479.

Siwe, S. A. (1933). Z. Kinderheilk., 55, 212. (Cited by Abt and Denenholz.)

Van Creveld, S., and Ter Poorten, F. H. (1935). Arch. Dis. Childh., 10, 125.

Wallgren, A. (1940). Amer. J. Dis. Child., 60, 471.

Weinstein, A., Francis, H. C., and Sprofkin, B. F. (1947). Arch. intern. Med., 73, 176. 